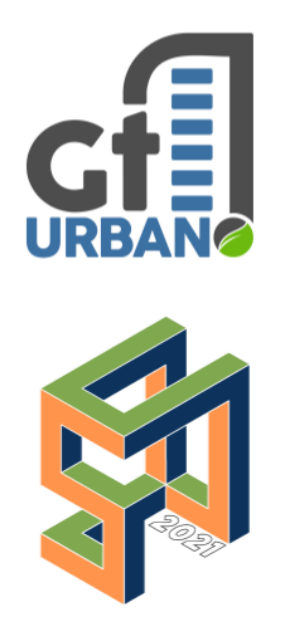

SINGEURB

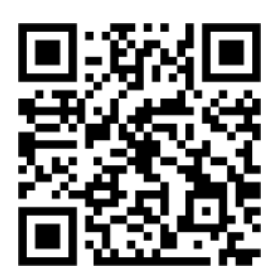

Como citar:

MARINS et al.

Impacto do

zoneamento no

desenvolvimento do

uso do solo do

entorno de estações

de transporte

selecionadas no

município de São

Paulo. In: III

SIMPÓSIO

NACIONAL DE

GESTÃO E

ENGENHARIA

URBANA:

SINGEURB, 2021,

Maceió. Anais...

Porto Alegre:

ANTAC, 2021. p. 290-

299.

Disponível em:

https://eventos.antac.

org.br/index.php/sin

geurb/issue/view/14

\title{
Impacto do zoneamento no desenvolvimento do uso do solo do entorno de estações de transporte selecionadas no município de São Paulo
}

Impact of the zoning on the development of land use around selected transport stations in the municipality of São Paulo

Karin Regina de Castro Marins, Escola Politécnica da Universidade de São

Paulo (USP), karin.marins@usp.br

Thales Tadeu Bendilati, Escola Politécnica da Universidade de São Paulo (USP), thales.tadeu@usp.br

Mariê Xavier Clementino, Escola Politécnica da Universidade de São Paulo (USP), marie.clementino@usp.br

Rafael Barreto Castelo Cruz, Escola Politécnica da Universidade de São

Paulo (USP), rafaelcastelo@usp.br

Vinicius Lima, Escola Politécnica da Universidade de São Paulo (USP), lima.vinicius@usp.br

Thiago Canhos Montmorency Silva, Escola Politécnica da Universidade de São Paulo (USP), lima.vinicius@usp.br

Gabriel Maggio Moraes, Escola Politécnica da Universidade de São Paulo (USP), gabriel.maggio@usp.br

Emílio Bertholdo Neto, Escola Politécnica da Universidade de São Paulo (USP), emilio.bneto@usp.br

Carolina Hitomi Okamoto, Escola Politécnica da Universidade de São

Paulo (USP), carollina.okamoto@usp.br

Filipe Sena, Escola Politécnica da Universidade de São Paulo (USP),

filipe.sena@usp.br

Christian Nazareth Teixeira, Escola Politécnica da Universidade de São

Paulo (USP), christian.nazareth.t@usp.br

\section{RESUMO}

$\mathrm{O}$ zoneamento se destaca dentre os instrumentos de planejamento urbano, pois permite direcionar, condicionar e controlar o desenvolvimento urbano, especialmente em áreas de desenvolvimento orientado ao transporte. Este é o caso do município de São Paulo, que estabeleceu em seu Plano Diretor de 2014 e Lei de Zoneamento de 2016, as Zonas Eixo de Estruturação e Transformação Urbana (ZEU) e Eixo de Estruturação e Transformação Urbana Previsto (ZEUP), para adensar e qualificar os entornos das estações de transporte de massa. O objetivo desse trabalho é analisar a distribuição das zonas de uso e ocupação do solo em 
áreas de influência de um quilômetro de estações de transporte selecionadas no município de São Paulo - Tatuapé, Tucuruvi, Vila Prudente e Lapa. Foram processadas bases georreferenciadas da Prefeitura no software QGIS, relativamente ao zoneamento vigente e às outorgas onerosas concedidas entre 2000 e 2019. O trabalho é produto de pesquisa desenvolvida por docente, pós-doutorando, pósgraduandos e graduandos. Os resultados mostram que há grande heterogeneidade no zoneamento constante do raio de abrangência analisado, sendo, em média, apenas $1 / 3$ do território classificado como ZEU/ZEUP e que a ausência dessas zonas, como no caso da Lapa, pode ter afetado a atratividade da região por novos empreendimentos.

Palavras-chave: Instrumentos de planejamento urbano, DOT, Adensamento construído.

\begin{abstract}
Zoning stands out among urban planning instruments, as it allows directing, conditioning and controlling urban development, especially in transit-oriented development areas. This is the case of the municipality of São Paulo, which established in its 2014 Master Plan and 2016 Zoning Law, the Axis Zones of Urban Structuring and Transformation (ZEU) and the Planned Axis Zones of Urban Structuring and Transformation (ZEUp), aiming at densifying and qualifying the surroundings of mass transport stations. The objective of this work is to analyze the distribution of land use zones in areas of influence of one kilometer of selected transport stations in the city of São Paulo - Tatuapé, Tucuruvi, Vila Prudente and Lapa. Georeferenced databases of the Municipality were processed in the QGIS software, in relation to the current zoning and the onerous grants payed between 2000 and 2019. The work is the product of research carried out by professor, post-doc, graduates and undergraduates. The results show a great heterogeneity in the zoning of the analyzed coverage radius, being, on average, only $1 / 3$ of the territory classified as ZEU/ or ZEUp. Moreover, the absence of these zones, as in the case of Lapa, may have affected the attractiveness of the region by new developments.
\end{abstract}

Keywords: Urban planning instruments, TOD, Built density.

\title{
1 INTRODUÇÃO
}

O zoneamento municipal é um dos instrumentos de planejamento e desenvolvimento urbanos mais importantes, difundidos e utilizados no Brasil. Estabelece os usos e formas de ocupação incentivadas, desincentivadas, permitidas e proibidas, além de mecanismos de incentivo e controle do desenvolvimento urbano, orienta aspectos de aproveitamento e uso do espaço urbano, bem como de sua qualificação social e ambiental. Relacionado dentre os instrumentos de ordenamento territorial no Estatuto da Cidade (BRASIL, 2001), o zoneamento é constituído sob a forma de política pública municipal, condicionando o adensamento e a verticalização urbanos, as relações de vizinhança, a demanda por infraestrutura e o mercado imobiliário.

Ao zoneamento municipal podem se integrar diversos outros instrumentos de planejamento e desenvolvimento urbano, tais como as zonas especiais de interesse social (ZEIS) e a outorga onerosa do direito de construir. Um levantamento realizado pelo IBGE (2019) identificou que mais de $90 \%$ dos municípios brasileiros com mais de 20.000 habitantes, possuíam plano diretor, conforme preconiza a Constituição Federal de 1988. Dos 5.570 municípios do país, 61,9\% têm legislação sobre zoneamento ou 
uso e ocupação do solo, 55,1\% têm legislação sobre ZEIS e 40,3\%, legislação sobre outorga onerosa do direito de construir, ou solo criado, conforme Figura 1.

No município de São Paulo, o zoneamento vigente se estabeleceu em 2016 com a Lei de Parcelamento, Uso e Ocupação do Solo - LPUOS (PMSP, 2016), baseada no Plano Diretor Estratégico de 2014 (PMSP, 2014), que redefiniu a distribuição de zonas e respectivos parâmetros urbanísticos, com o objetivo principal de "humanizar e reequilibrar São Paulo, aproximando moradia e renda e enfrentando as desigualdades socioterritoriais". Dessa forma, o entorno de diversas estações de transporte de massa, em um raio médio de $500 \mathrm{~m}$, foi revalorizado por meio da definição de uma zona específica, denominada Zona de Estruturação Urbana (ZEU). A ZEU é voltada ao adensamento populacional e construtivo, e promoção do desenvolvimento de centralidades locais, com incentivos ao uso misto, comércio voltado para as vias e circulação local a pé. Além da ZEU, o zoneamento demarca as Zonas de Estruturação Urbana Prevista (ZEUp), que trazem características de uso e ocupação do solo semelhantes à ZEU, as quais serão ativadas quando um dado eixo de transporte previsto entrar em operação.

Figura 1 - Percentual de municípios com instrumentos de planejamento

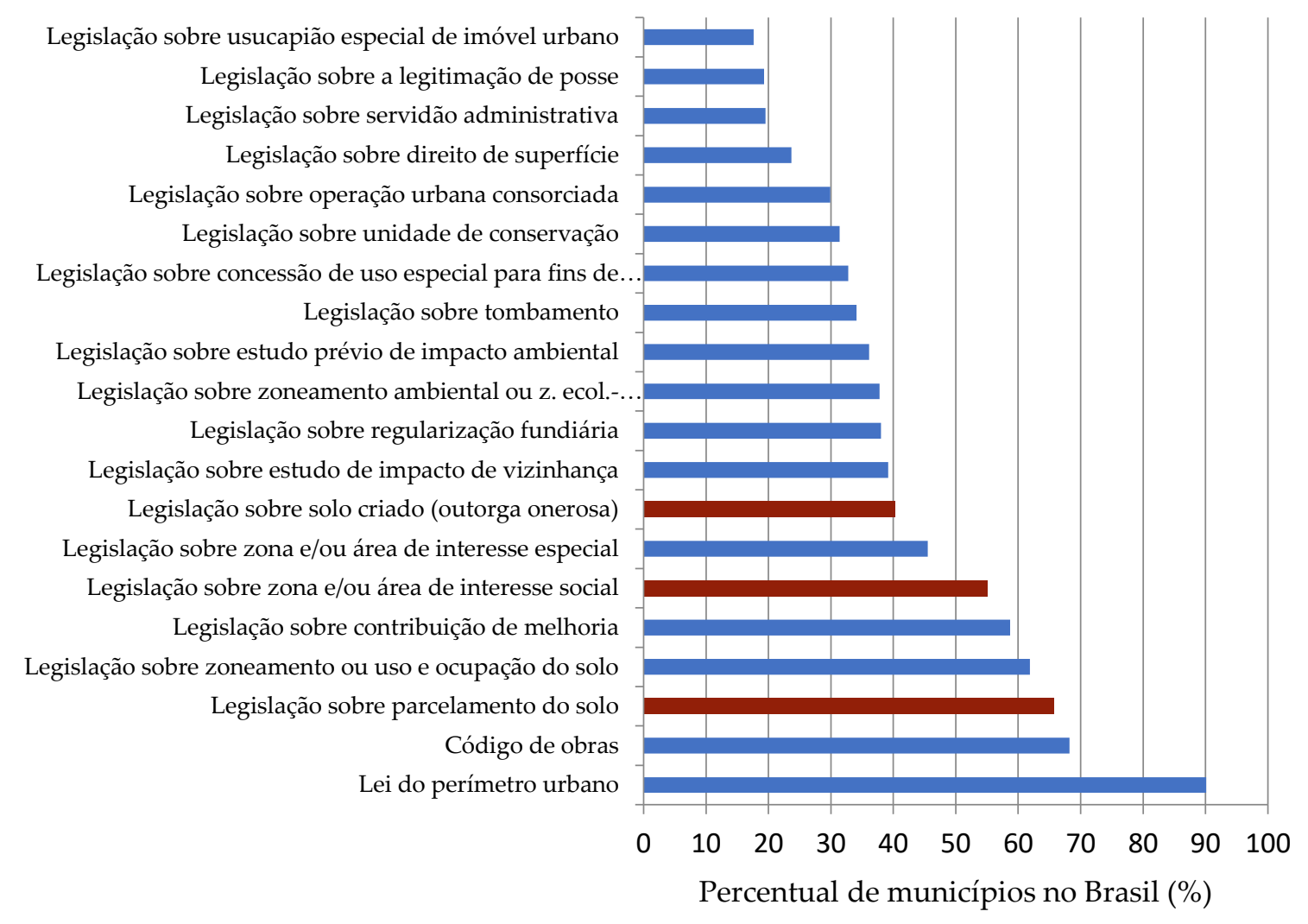

Fonte: Adaptado de IBGE (2019)

Entretanto, a configuração da ZEU gera alguns questionamentos quanto à efetividade dos territórios demarcados para a promoção da caminhabilidade como importante meio de mobilidade urbana, assim como da integração das políticas de promoção de empreendimentos, inclusive habitação de interesse social. 
O objetivo desse trabalho é analisar a distribuição das zonas de uso e ocupação do solo em áreas de influência de um quilômetro de estações de transporte selecionadas no município de São Paulo, conforme lei de zoneamento vigente desde 2016, confrontando-a com a localização e a concentração de novos empreendimentos imobiliários sujeitos ao pagamento da outorga onerosa, portanto, empreendimentos com maior potencial construtivo agregado.

\section{METODOLOGIA}

A análise é pautada no estudo do raio de um quilômetro no entorno das estações do Tatuapé, do Metrô/ Trem (CPTM), Tucuruvi, do Metrô, Vila Prudente, do Metrô, e Lapa, de Trem (CPTM, linha Rubi). Essas estações estão em diferentes regiões do município de São Paulo e apresentam entornos com configurações morfológicas distintas, mas em crescente processo de adensamento urbano.

A distância de $1 \mathrm{~km}$ foi definida com base na indicação da literatura para possíveis distâncias caminháveis de 1 até $1,5 \mathrm{~km}$, o que, aproximadamente, estaria nesse raio de influência (ITDP, 2017). Além disso, avaliando as distâncias caminhadas pelos entrevistados da Pesquisa Origem e Destino (OD) da Região Metropolitana de São Paulo (RMSP) de 2017, é observada uma concentração maior de viagens entre 1 a 1,6 $\mathrm{km}$ (Tabela 1), o que reforça a escolha do raio adotado nesse estudo.

Tabela 1 - Distribuição da distância de caminhada na RMSP em 2017

\begin{tabular}{|c|c|c|c|c|}
\hline $\begin{array}{c}\text { Tempo de } \\
\text { caminhada (min) }\end{array}$ & $\begin{array}{l}\text { Velocidade média de } \\
\text { caminhada }(\mathrm{km} / \mathrm{h})\end{array}$ & $\begin{array}{l}\text { Distância máxima de } \\
\text { referência }(\mathrm{m})\end{array}$ & $\begin{array}{l}\text { Número de } \\
\text { viagens }\end{array}$ & $\%$ das viagens \\
\hline até 10 & 5 & até 833 & 147 & 6,3 \\
\hline $10-20$ & 5 & de 833 a 1.666 & 772 & 33,1 \\
\hline 20 a 30 & 5 & de 1.666 a 2.500 & 515 & 22,1 \\
\hline 30 a 40 & 5 & de 2.500 a 3.333 & 486 & 20,8 \\
\hline \multirow[t]{2}{*}{ mais de 40} & 5 & mais de 3.333 & 413 & 17,7 \\
\hline & & Total & 2333 & 100,0 \\
\hline
\end{tabular}

Fonte: Os autores (2021), utilizando dados da Pesquisa OD da RMSP (CMSP, 2017).

As bases georreferenciadas da plataforma Geosampa da Prefeitura de São Paulo, relativamente às quadras e legislação de uso e ocupação do solo, bem como cadastro de empreendimentos construídos mediante pagamento da outorga onerosa do direito de construir, até 01/06/2019 (PMSP, 2021), foram processadas no QGIS 3.10 ou superior.

\section{3 ÁREAS URBANAS ESTUDADAS}

As áreas estudadas foram selecionadas conforme parâmetros de densidade populacional e de empregos, índice de compactação e de diversidade de uso, analisados nas 32 subprefeituras do município, expostos em Cruz, Marins e Kurokawa (2021), combinados com a análise da circulação de pessoas para acesso às estações de transporte, seguindo resultados da Pesquisa OD da RMSP (CMSP, 2017). 
Conforme mapa da Figura 2, a estação do Tatuapé tem seu perímetro de análise dentro da subprefeitura da Mooca, e a estação do Tucuruvi e sua área de influência estão localizados na subprefeitura de SantanaTucuruvi. Já os entornos das estações da Lapa e Vila Prudente estão localizados nas subprefeituras de mesmo nome.

Figura 2 - Localização das áreas de estudo nas subprefeituras do município de São Paulo

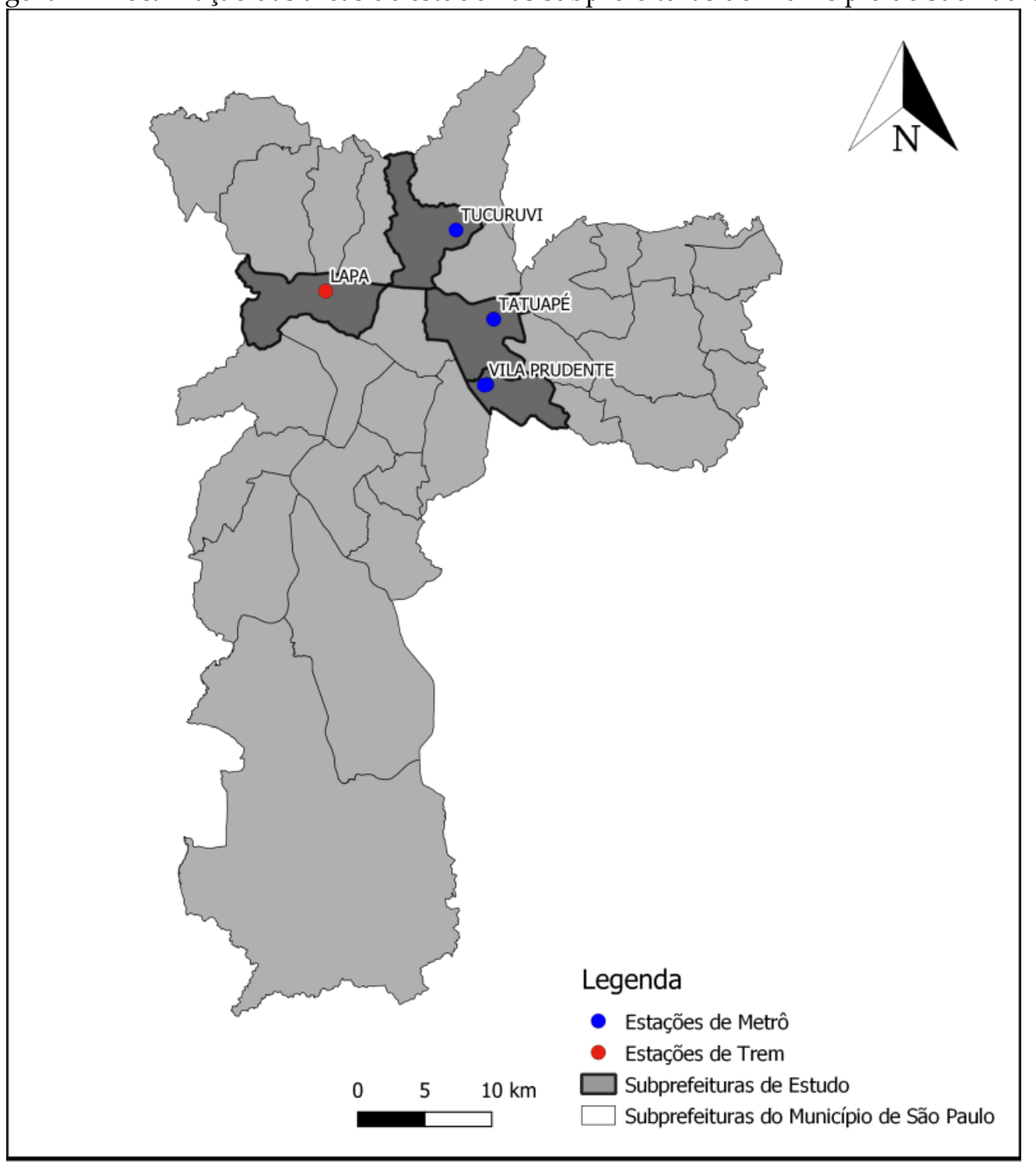

Fonte: Os autores (2021), utilizando dados de Geosampa (PMSP, 2021)

Os instrumentos da política urbana orientam as práticas de uso e ocupação de solo, que podem ser avaliadas por meio de índices e indicadores. Para as divisões administrativas consideradas (Tabela 2), nota-se que as densidades populacionais variam de 75 a 135 hab./ha, sendo a média municipal de 73hab./ha. No que se refere à densidade de empregos, as áreas estudadas tem de $35 \mathrm{emp}$./ha a $97 \mathrm{emp}$./ha, quando a média municipal é da ordem de $39 \mathrm{emp}$./ha. Do ponto de vista territorial, as áreas possuem índice de compacidade de 0,594 a 0,792, configurando áreas compactas. Quanto à diversidade, os valores variam entre 0,212 e 0,480, o que as caracteriza de pouco diversa a diversa, no caso da Vila Prudente. 
Tabela 2 - Caracterização das subprefeituras da Lapa, Mooca, Santana-Tucuruvi e Vila Prudente, no município de São Paulo

\begin{tabular}{ccccccc}
\hline Subprefeitura & $\begin{array}{c}\text { Dens. } \\
\text { Populac. } \\
\text { (hab/ha) }\end{array}$ & $\begin{array}{c}\text { \% do } \\
\text { município }\end{array}$ & $\begin{array}{c}\text { Dens. } \\
\text { empregos } \\
\text { (trab./ha) }\end{array}$ & $\begin{array}{c}\text { \% do } \\
\text { município }\end{array}$ & $\begin{array}{c}\text { Índice de } \\
\text { Diversidade }\end{array}$ & $\begin{array}{c}\text { Índice de } \\
\text { Compacidade }\end{array}$ \\
\hline Lapa & 75 & 1,51 & 97 & 6,40 & 0,245 & 0,594 \\
\hline Mooca & 95 & 2,56 & 86 & 5,50 & $0,24.0$ & 0,665 \\
\hline Santana - Tucuruvi & 91 & 2,18 & 35 & 2,50 & 0,212 & 0,568 \\
\hline Vila Prudente & 135 & 4,47 & 84 & 5,20 & 0,480 & 0,792 \\
\hline
\end{tabular}

Fonte: Adaptado de Cruz, Marins e Kurokawa (2021)

\section{RESULTADOS}

A Figura 3 mostra o mapeamento do zoneamento das áreas urbanas estudadas, conforme LPUOS vigente desde 23/03/2016 no município de São Paulo; já a Tabela 3 traz a distribuição percentual das zonas consideradas.

Na Vila Prudente, Tatuapé e Tucuruvi, verifica-se a demarcação da ZEU em um raio médio de 500m a partir das respectivas estações de metrô e também a demarcação da ZEUp, indicando a possível continuidade do padrão de desenvolvimento. Essas três áreas também contam com a presença marcante de Zona de Estruturação Metropolitana (ZEM), Zona de Centralidade (ZC) e Zona de Desenvolvimento Econômico (ZDE) nas proximidades das estações. Essas outras zonas permitem passar do coeficiente de aproveitamento básico de 1 para coeficiente de aproveitamento máximo de 2 mediante pagamento da outorga onerosa, porém não trazem o mesmo conjunto de estratégias previstas para a ZEU, relativamente à inserção dos empreendimentos no bairro e, tais como incentivos aos usos mistos, fachada ativa, fruição pública e alargamentos de calçadas.

Já no entorno da estação da Lapa, verifica-se a predominância absoluta da ZEM e ausência de ZEU, o que reduz o potencial construtivo máximo dos empreendimentos da região.

Tabela 3 - Percentual das zonas de uso e ocupação do solo nas áreas urbanas estudadas

\begin{tabular}{|c|c|c|c|c|c|}
\hline$\%$ Zonas & Lapa & Tatuapé & Tucuruvi & V. Prudente & $\begin{array}{c}\text { Média das } \\
\text { áreas estudadas }\end{array}$ \\
\hline ZEU & 0 & 35,10 & 35,40 & 25,93 & 23,94 \\
\hline ZEUp & 0 & 18,43 & 7,60 & 9,49 & 8,79 \\
\hline ZEIS & 0,11 & 4,22 & 0,60 & 4,90 & 2,41 \\
\hline ZEM, ZC e ZDE & 75,56 & 13,88 & 22,50 & 16,48 & 32,50 \\
\hline Outras zonas & 24,22 & 28,37 & 33,90 & 43,21 & 32,36 \\
\hline
\end{tabular}

Fonte: Os autores (2021), utilizando dados de Geosampa (PMSP, 2021) 
Ainda quanto ao zoneamento, a participação de ZEIS é minoritária na proximidade de $1 \mathrm{~km}$ das estações, o que gera discussões sobre a efetividade do zoneamento quanto ao objetivo de reequilíbrio socioterritorial do Plano Diretor de São Paulo, já que nenhuma das demais zonas traz parâmetros de incentivo ou obrigatoriedade relativamente à diversidade de provimento habitacional que inclua a população de baixa renda.

Figura 3 - Zoneamento vigente nas áreas estudadas no município de São Paulo: Tatuapé (A), Vila Prudente (B), Lapa (C) e Tucuruvi (D)
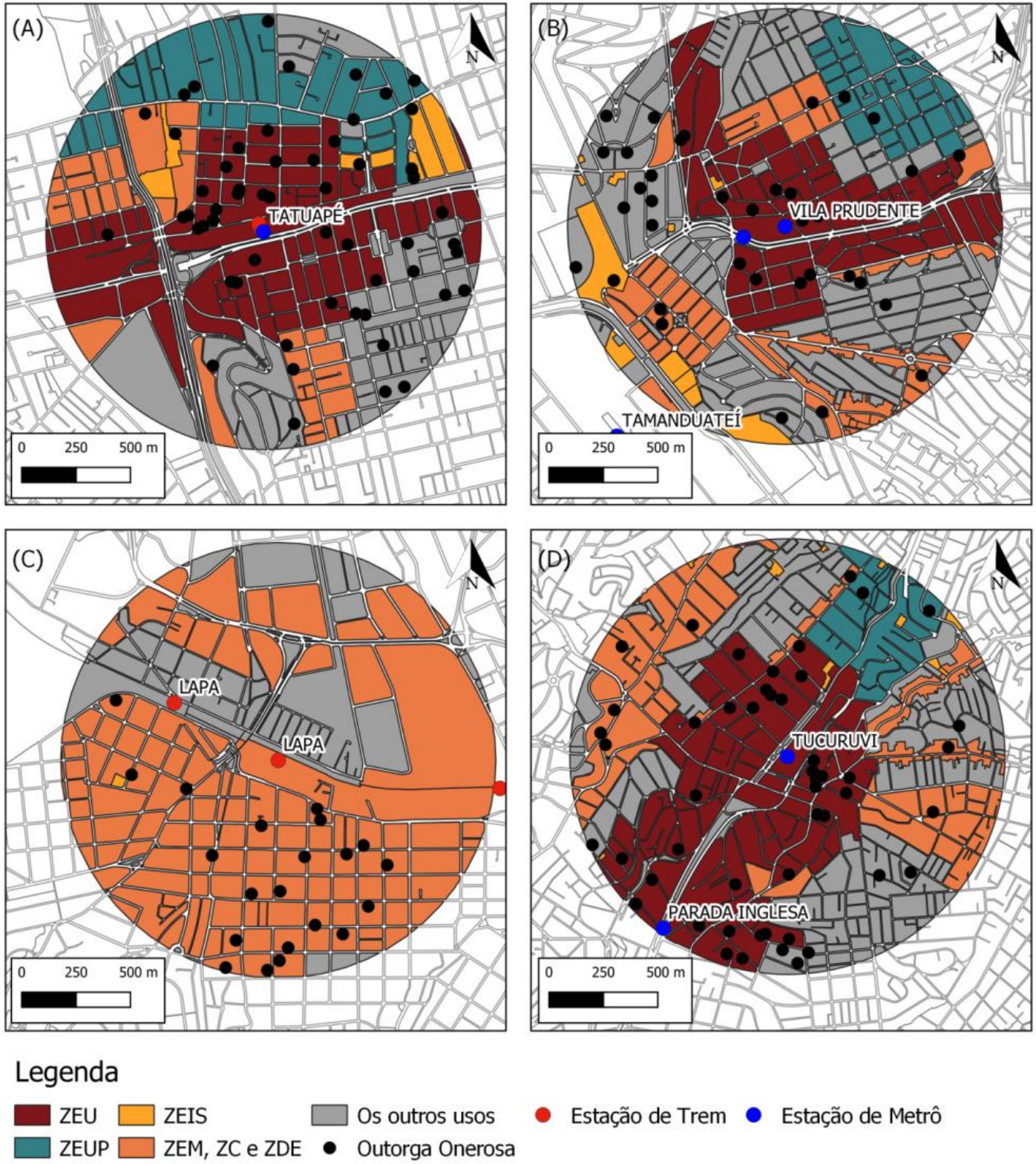

- Estação de Trem

Estação de Metrô

Fonte: Os autores (2021), utilizando dados de Geosampa (PMSP, 2021)

Adicionalmente, a Figura 3 mostra a localização dos empreendimentos com concessão de outorga onerosa de 2000 a 2019, nas áreas estudadas, e as Figuras 4 e 5, o quantitativo dessas concessões. Verifica-se um número significativo de empreendimentos anteriores a 2011, sobretudo na região da Lapa, ao passo que a Vila Prudente e o Tatuapé receberam um pico de intervenções entre 2011 e 2013. Das quatro áreas, 
somente o Tucuruvi desenvolveu um número mais expressivo de empreendimentos após a vigência da nova Lei de Zoneamento. Vila Prudente e Tatuapé tiveram uma quantidade intermediária de empreendimentos, enquanto a Lapa, apenas um.

Figura 4 - Outorgas onerosas concedidas de 2000 a 2019 nas áreas de estudo

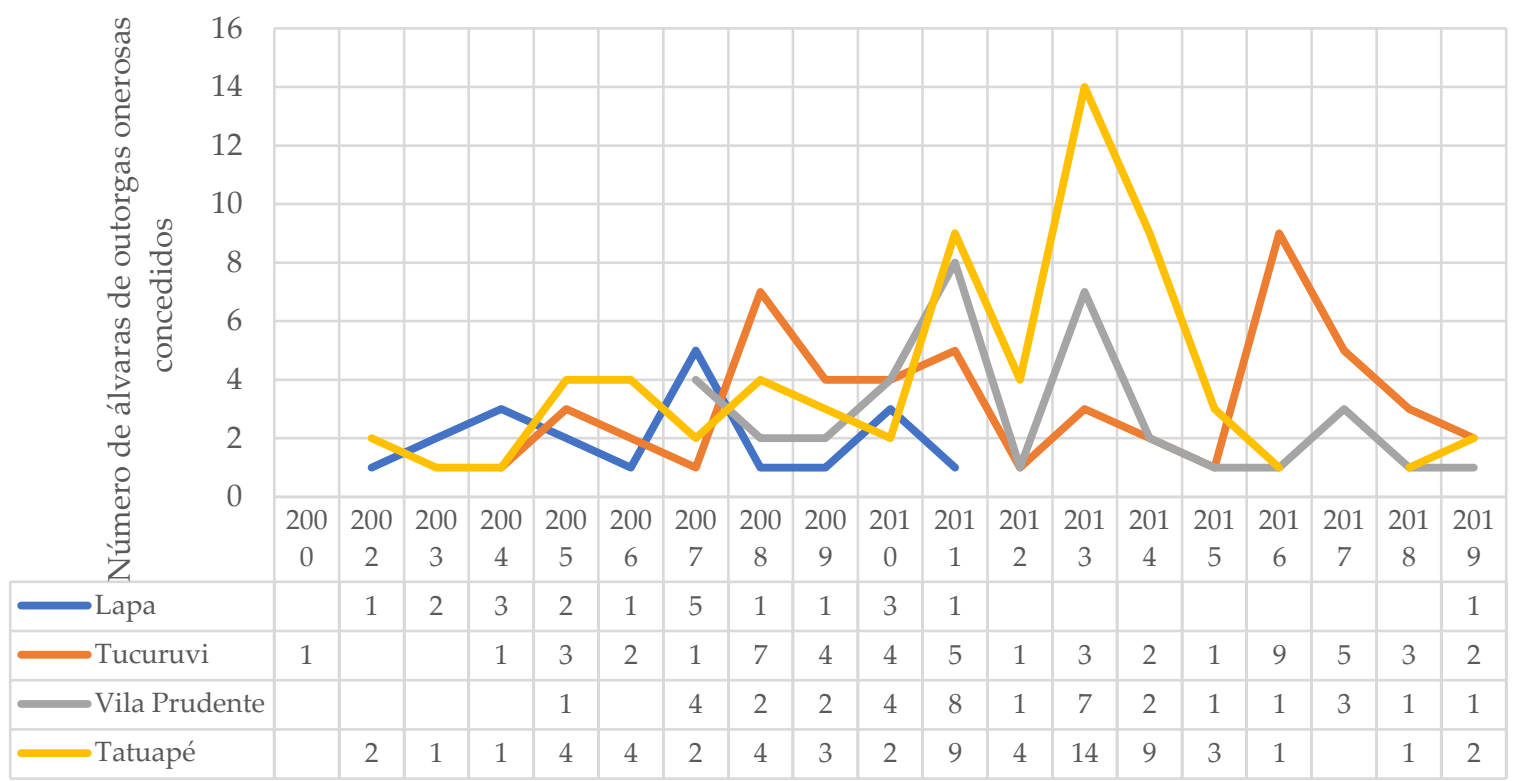

Ano de concessão

Fonte: Os autores (2021), utilizando dados de Geosampa (PMSP, 2021)

Figura 5 - Outorgas onerosas concedidas antes e após o zoneamento vigente, nas áreas de estudo

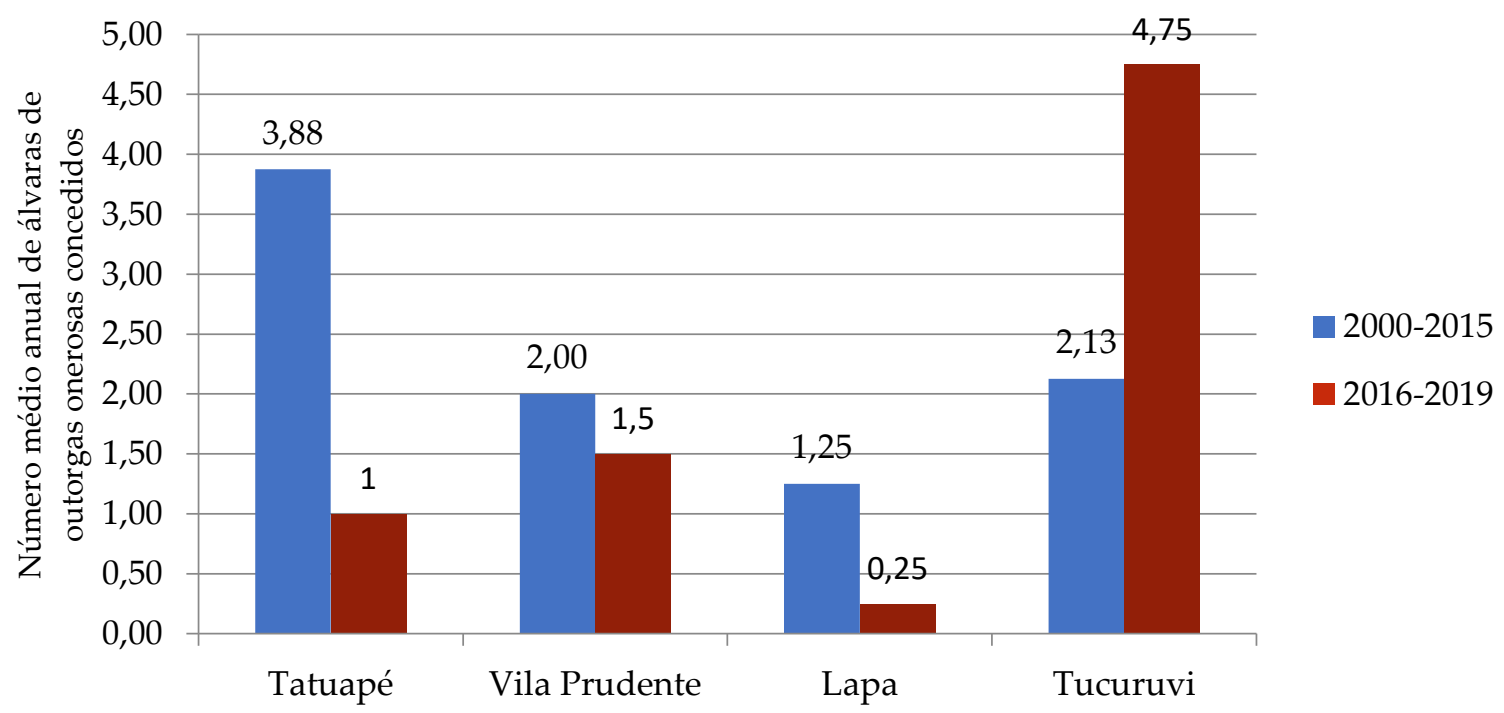

Fonte: Os autores (2021), utilizando dados de Geosampa (PMSP, 2021) 


\section{CONCLUSÕES}

Conforme embasamento conceitual, o entorno de $1 \mathrm{~km}$ de estações de transporte de massa corresponderia às áreas localizadas a uma distância caminhável destes equipamentos urbanos e passíveis de desenvolvimento de centralidades.

Os casos analisados no município de São Paulo mostram, entretanto, que há grande heterogeneidade no zoneamento constante desse raio de abrangência. Há porções do território demarcadas como ZEU e ZEUp em que o zoneamento é alinhado com as diretrizes do DOT - uso misto, densidade populacional integrada à densidade construída, alargamento de calçadas, fachada ativa, dentre outros - e estão presentes no Tatuapé, Vila Prudente e Tucuruvi. Entretanto, há porções consideráveis nessas áreas, mas, sobretudo, na Lapa, em que esse alinhamento não ocorre.

Verificou-se ainda, a demarcação da ZEU teve efeitos diferenciados na promoção do adensamento construído, nos casos estudados. No Tatuapé e na Vila Prudente, identificaram-se empreendimentos sujeitos à outorga onerosa implementados após o zoneamento novo, porém em quantidade inferior ao que vinha sendo praticado, e, no caso da Vila Prudente, superior à taxa anterior. Por outro lado, no caso da Lapa, foi constatada uma redução extrema desses empreendimentos, o que de certa forma indica que a falta de um zoneamento motivador do adensamento, pode ter afetado a atratividade da região por novos empreendimentos.

Dessa forma, no caso do município de São Paulo, é relevante o detalhamento de estratégias em nível local e o aperfeiçoamento dos atributos do zoneamento para alcance dos objetivos do Plano Diretor. Ainda, o monitoramento instrumentalizado e crítico dos parâmetros multicriteriais urbanos é fundamental para se proceder à melhoria da governança em desenvolvimento urbano.

\section{AGRADECIMENTOS}

Programas PIBIC/CNPq e PUB/ USP 2020/2021, pelas bolsas de iniciação cientifica.

\section{REFERÊNCIAS}

CMSP. Base de Dados Pesquisa Origem e Destino do Metrô de São Paulo .2017. Disponível em:< http://www.metro.sp.gov.br/pesquisa-od/>. Acesso em: 01 jul. 2021.

CRUZ, R.B.C; MARINS, K.R.C.; KUROKAWA, F.A. Multicriteria methodological-rational model to evaluated urban areas: A case study of the São Paulo City/Brazil. Sustainable Cities and Society, 67, April 2021, 102718.

IBGE. Pesquisa de informações básicas municipais. Rio de Janeiro: IBGE, 2019.

ITDP.TOD STANDARD. Padrão e Qualidade DOTS. 2017. Disponível em: < https://www.itdp.org/2017/06/23/tod-standard/>. Acesso em: 01 jul. 2021.

PREFEITURA DO MUNICÍPIO DE SÃO PAULO - PMSP. Lei n 16.050/ 2014. Aprova o Plano Diretor Estratégico do Município de São Paulo e revoga a Lei no 13.430/200. 2014. 
PREFEITURA DO MUNICÍPIO DE SÃO PAULO - PMSP. Lei n 16.402/2016. Lei de Parcelamento, Uso e Ocupação do Solo. Disciplina o parcelamento, o uso e a ocupação do solo no Município de São Paulo. 2016.

PREFEITURA DO MUNICÍPIO DE SÃO PAULO - PMSP. Plataforma Geosampa. Mapa Digital da Cidade de São Paulo. Disponível em: <http://geosampa.prefeitura.sp.gov.br/PaginasPublicas/_SBC.aspx\#>. Acesso em: 28 jun. 2021 